\title{
CONVERGENCE CRITERIA FOR AFRICAN MONETARY UNIONS: BRINGING IN NON-ECONOMIC FACTORS AND COMPARING THE TURKISH CASE
}

\author{
Bala Batavia, DePaul University, Chicago, U.S.A. \\ Cheick Wagué, Southern Stockholm University-Södertörn, Sweden \\ Parameswar Nandakumar Warrier, Indian Institute of Management, Calicut, India
}

$\underline{\text { dx.doi.org/10.18374/JIFE-19-3.4 }}$

\begin{abstract}
The paper starts by noting that Turkey in her efforts to join the European Union and the European Monetary Union faces barriers that are non-economic in nature. Turkey is seen to be lagging behind the EU fraternity in providing complete democracy to its people. We find the strictures laid on to be rather unique, as such non-economic factors do not enter in, for instance, in discussions pertaining to regional monetary unions in Africa where a leader in economic performance may be a laggard in meeting non-economic convergence criteria. This paper develops non-economic convergence criteria, using five indices capturing the prevalence of democracy and freedom for the citizens, for regional African monetary unions in Africa, in West Africa and the CFA Franc Zone, and compare the convergence achieved by these nations with that of Turkey relative to the dominant economic player in Europe. It is noted that while Turkey lags behind in achieving convergence to the EU certain noneconomic factors, she does better in some others. Also, some African members of regional monetary unions are seen to fare worse that Turkey in converging to the specified non-economic criteria values.
\end{abstract}

Keywords: EURO, CFA Franc, Convergence Criteria, Optimum Currency, Democracy Index. 